\title{
Study on Mechanical Mechanism and Stability of Surrounding Rock in Fault Structure Roadway
}

\section{yuming lu}

Guilin University Of Aerospace Technology

Wang Wei ( $\nabla$ mcgs0920@163.com)

School of Energy and Building Environment,Guilin University Of Aerospace Technology, Gui Lin, Guangxi 541000

\section{Tang Zhiyu1}

School of Energy and Building Environment,Guilin University Of Aerospace Technology, Gui Lin, Guangxi 541000

\section{Original Paper}

Keywords: Roadway surrounding rock, fault, fault fracture zone, optimized support, numerical simulation

Posted Date: February 4th, 2021

DOl: https://doi.org/10.21203/rs.3.rs-180384/v1

License: (c) (i) This work is licensed under a Creative Commons Attribution 4.0 International License. Read Full License 


\title{
Study on mechanical mechanism and stability of
}

\section{surrounding rock in fault structure roadway}

\author{
Lu Yuming ${ }^{1}$ Wang $\mathrm{Wei}^{1}{ }^{1}{ }^{*}$ Tang Zhiyu ${ }^{1}$
}

(1. School of Energy and Building Environment, Guilin University Of Aerospace

Technology, Gui Lin, Guangxi 541000； )

\begin{abstract}
In order to study the deformation and failure mechanism of the fault passage, this paper makes a series of research on the fault passage through theoretical analysis, field investigation and numerical simulation. Firstly, the mechanical characteristics of the fault structure and the deformation and failure characteristics of the surrounding rock passing through the fault are summarized. Then, the numerical analysis is carried out before and after the tunnel passing through the fault. The results show that the original support scheme has large deformation and failure in the surrounding rock of the fault section, and the deterioration and expansion of the plastic zone leads to the failure of the support. Finally, the comprehensive support scheme and principle of "bolt + anchor cable + metal mesh + grouting" is put forward, and the support for the broken tunnel passing through the fault is strengthened. The calculation results show that the support scheme can keep the tunnel passing through the fault in a stable deformation range, which is conducive to the long-term stability of the surrounding rock.
\end{abstract}

Keywords: Roadway surrounding rock; fault; fault fracture zone; optimized support; numerical simulation

\section{Introduction}

China's coal resources in the past 20 years with a relatively stable growth rate, with the improvement of mining technology, as well as the consumption of shallow resources, China's coal is gradually entering deep mining. In this context, China's new roadways can reach 10,000 kilometers per year ${ }^{[1]}$. Many roadways in the deep high stress, roadway support difficulties, large deformation, fluid damage is increasingly prominent. At present, there are many coal seam mining lanes often can not avoid some complex tectonic geological con- ditions, such as faults, broken belt and so on ${ }^{[2-4]}$. After the roadway crosses the fault, it is generally affected by large tectonic 
stress. On the one hand, the maximum main stress direction of the laneway is deflected, on the other hand, it will weaken the strength of the rock body around the laneway and make the rock formations have no continuous distribu- tion ${ }^{[5]}$. Therefore, once the roadway is faced with the geological structure of large faults, if not to take effective support measures or in accordance with the normal construction rules to deal with the roadway fault zone, once the roadway under high tectonic stress, it is easy to occur support difficulties, roadways can not be used normally. In order to meet the demand and safety requirements, roadways often re- quire secondary or multiple repairs to main- tain the stability of the surrounding rock, which brings many outstanding problems to mining safety and efficiency. Therefore, many scholars pay attention to the deformation and destruction mechanism of this kind of fault roadway, and have made some research results in theory, indoor test and field application. For example, Zhang Mingzhong and so on ${ }^{[2]}$ studi- ed the characteristics of the deep roadway through the large fault broken surrounding rock, and compared the situation of the no-fault formation roadway surrounding rock, established a suitable for the oversteed fault roadway support principle and method; Zhang Mingqiang ${ }^{[9]}$ put forward a comprehensive support means of anchor net rope and slurry when the top plate is broken and sunk when the roadway is close to the fault, and the support effect is obvious. Meng Zhaoping and others ${ }^{[10]}$ carried out detailed indoor laboratory tests on coal rocks near faults, and carried out numerical tests to systematically reveal the effects of positive faults on the physical and physical properties of coal and the distribution of mineral pressure. At present, many roadway fault support means or follow the traditional design methods as a reference, and these support means can not meet the support re- quirements ${ }^{[1-14]}$. There is no more in-depth and systematic research on the influence of the fault roadway on the range of surrounding rock plastic area, the support structure and the optimization of the support mode. Therefore, this paper analyzes the characteristics of fault laneways through theory, and establishes the extended forces model of hidden faults and the critical model of burst water. According to the actual roadway fault as the engineering background, using Flac ${ }^{3 \mathrm{D}}$ numerical simula- tion software to explore the deformation of the cross fault lane, consider the impact of the support design on the stability of the roadway, and carry out optimization research, for such a fault roadway stability and deformation of the understanding of a certain reference and re- ference. 


\section{Analysis of fault structure characteristics}

\subsection{Fault breaking banding characteristics}

After the rock formation breaks, a relative slip surface is produced, which causes the rock layer to be in a state of indesemination, and this face refers to the fault plane. Figure 1 is a brief diagram of the positive fault, which mainly includes the fault plane, fault line, upper and lower plate cross-face line and so on. When the rock formations break, the formation of the upper and lower plates will squeeze each other, so that the surface of the fault on both sides of the further squeeze broken, over time so that the accumulation of broken rocks to form a clear band structure with a certain thickness, also known as a fault zone or fault belt. Because the rock and soil body in the fracture zone shows the plastic characteristics of ano-heterogeneousness, the width of the crushing belt is an important factor in understanding the structural and technical characteristics of faults. Among them, fault breakage band width and fault influence band width and rock formation variation are closely related to fault formation type, geos stress intensity direction and rock nature.

In the process of disorting and squeezing the upper and lower parts of the fault, a large number of fissures will occur in the rock body within the fault range, and the fault rock will be divided into discrete block structures. Therefore, according to the integrity degree of the rock body, fault rock can be divided into broken belt and crack development zone (Figure 2), and the fault breaking zone will form a process of temperature, pressure and fracture development from high to low evolution, the corresponding structure and stress environment complex and variable. 
From the fracture center to the driving plate side

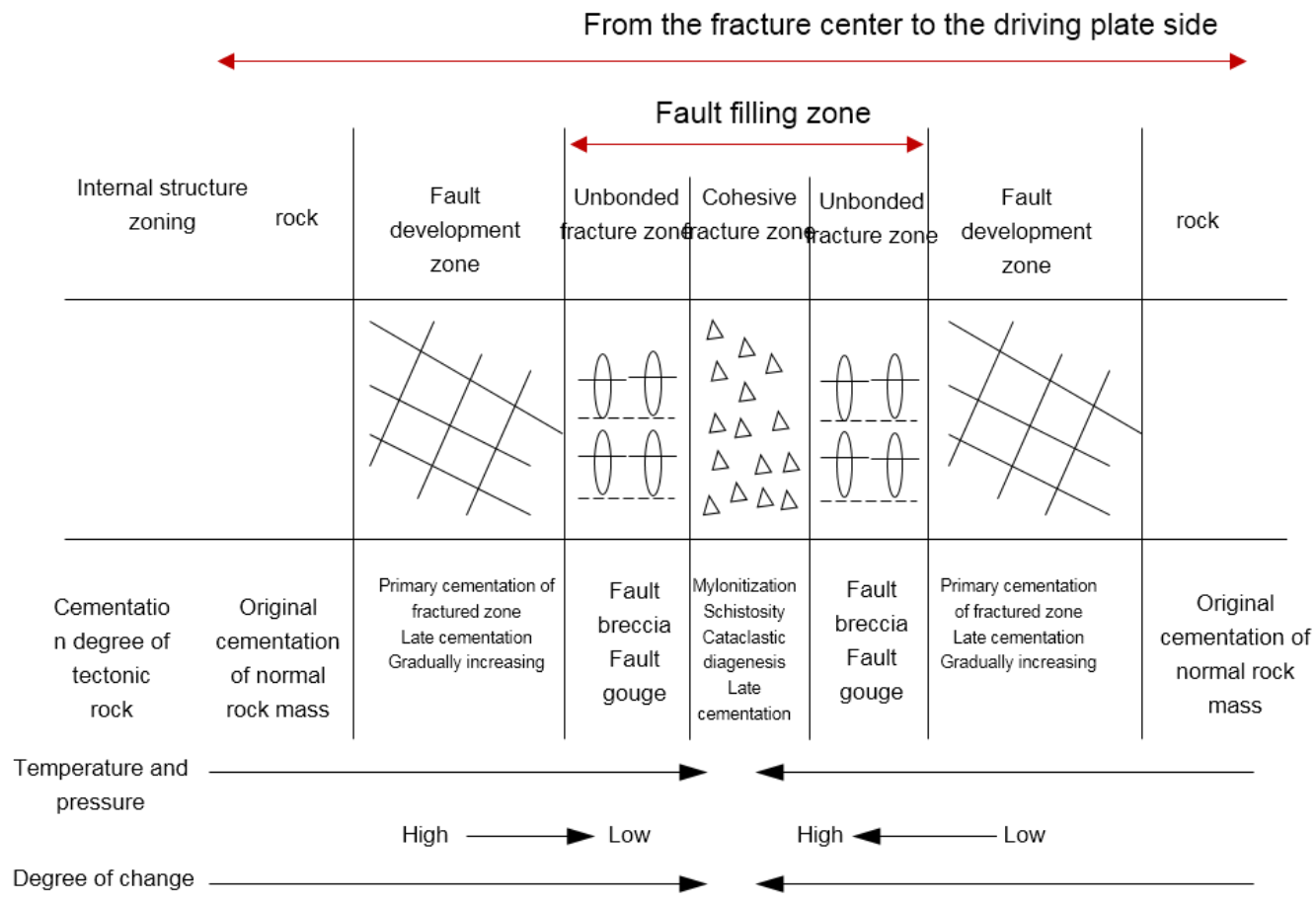

Fig. 1 Characteristics of zoning in fault zone.

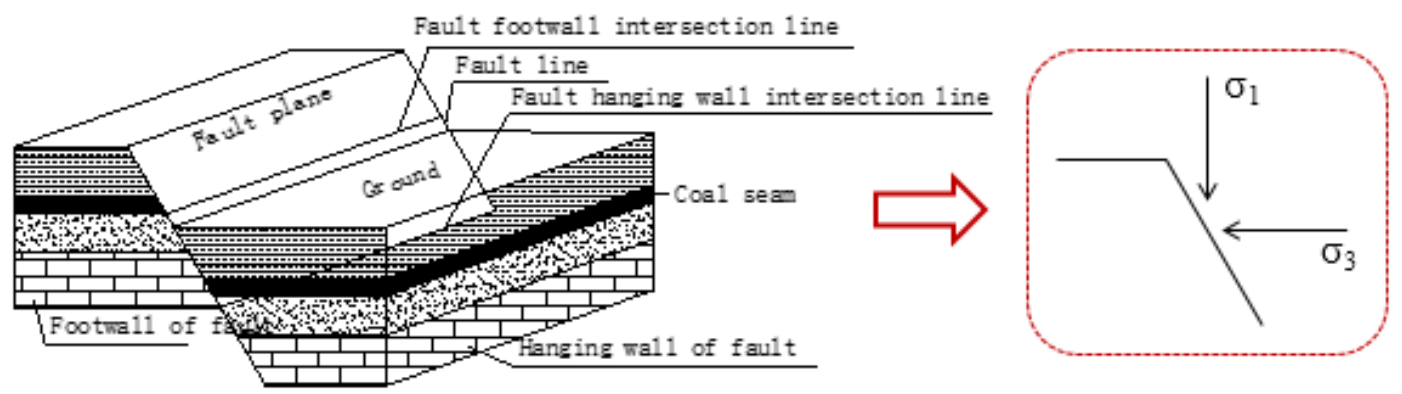

80

Fig. 2 Schematic diagram of coal bearing normal fault

\subsection{Stability criterion of faults}

As shown in Figure 2, if the fault reaches a stable condition, the ratio of maximum and minimum principal stress is ${ }^{[15]}$ :

$$
K=\frac{\sigma_{1}}{\sigma_{3}}=\frac{\tan \alpha-\tan \varphi}{1+\tan \alpha \tan \varphi}=\tan (\alpha-\varphi)
$$

Where: $\alpha$ is the angle between the direction of the fracture surface and the direction of the maximum principal stress, ${ }^{\circ}$; 
The change of $K$ value is related to fault $\operatorname{dip} \alpha$ and fault friction angle $\varphi$. If the fault $\operatorname{dip} \alpha$ value is fixed, the $K$ value decreases as the fault friction angle $\varphi$ increases. If the fault friction angle $\varphi$ value is fixed, the $K$ value increases as the fault dip $\alpha$ increases. (1) indicates that the maximum and minimum principal stress ratio $K$ has a critical value of 1 , that is, when $K$ is greater than $1, \sigma_{1}>\sigma_{3}$, then vertical stress is regarded as the maximum principal stress; on the contrary, horizontal stress is considered to be the maximum principal stress.

The roadway crossing the broken zone of the fault structure will cause the change of the direction of its principal stress, which will affect the change of the principal stress value, literature ${ }^{[16-19]}$ shows that the change of the middle principal stress of the roadway is mainly related to the ratio of the maximum and minimum principal stress before and after the active of the large fault or hidden fault. The greater the ratio of the two, the greater the intermediate principal stress. Among them, the main stress changes of normal faults before and after the formation of the fault structural zone are shown in Table 1.Table 1 Main stress change of normal fault

\begin{tabular}{|c|c|c|c|c|}
\hline \multirow[t]{2}{*}{ Item } & \multicolumn{2}{|c|}{ Before the fault } & \multicolumn{2}{|c|}{ After the fault } \\
\hline & $\sigma_{1}$ & $\sigma_{3}$ & $\sigma_{1}$ & $\sigma_{3}$ \\
\hline Normal fault & $\gamma H$ & $\frac{\sigma_{1}-\sigma_{c}}{\tan \alpha^{2}}$ & $\gamma H$ & $\gamma H \cot (\alpha-\varphi)$ \\
\hline
\end{tabular}

\subsection{The mechanism of hydraulic inrush activation by hidden faults}

At present, domestic coal mines are gradually entering deep mining, and disasters such as high water pressure and high gas pressure in the depths occur frequently. Excessive faults in the roadway will cause difficulties in support; in addition, many hidden small faults and small structures are under the action of mining and confined water, which pose a prominent threat to coal production. Current prevention and control methods are often unable to effectively predict and prevent. The activation mechanics of hidden faults plays an important role in understanding problems such as water inrush caused by fault activation.

For this reason, we think that the structure of the hidden fault can be regarded as a crack with some frictional effect, so that the active equivalent of the hidden fault with mining can be a crack expansion force model, as shown in Figure 3. The stress intensity factor at the tip of a hidden fault consists of three types: shear stress, confined water and normal stress. The stress intensity factors 
can be superimposed on each other to obtain the composite stress intensity factor of the hidden fault tip extension. Among them, there is the following relationship between the propagation stress $G$ and the intensity factor $K$ of the hidden fault crack $^{[20-21]}$ :

$$
G=\left(K_{\mathrm{II} \tau_{n}}^{2}+K_{\mathrm{I} p}^{2}+K_{\mathrm{I} \sigma_{n}}^{2}\right) / E
$$

Where: $K_{\mathrm{I} p}$ is the stress intensity factor of confined water; $K_{\mathrm{I} \sigma_{n}}$ is the normal stress intensity factor; $K_{\mathrm{II} \tau_{n}}$ is the shear stress intensity factor; $\mathrm{E}$ is the elastic modulus.

$$
\left.\begin{array}{l}
\sigma_{n}=\frac{\sigma_{1}[(1+\lambda)+(1-\lambda) \cos 2 \alpha]}{2} \\
\tau_{n}=\frac{(1-\lambda)}{2} \sigma_{1} \sin 2 \alpha
\end{array}\right\}
$$

Where: $l$ is the length of the concealed fault crack; $\sigma_{n}$ and $\tau_{n}$ are the principal stress and shear stress on the concealed fault respectively; $\sigma_{1}$ is the vertical stress; $\alpha$ is the dip angle of the concealed fault; $\lambda$ is the lateral pressure coefficient, and \pm respectively represents the positive concealed fault and Reverse concealed fault.

The crack growth resistance $R$ is a function of the amount of crack growth ${ }^{[20-21]}$ :

$$
R=\left[G_{c}^{m}+\frac{\left(l-l_{0}\right)}{m}\right]^{\frac{1}{m}}
$$

Where: $G_{\mathrm{c}}$ is the critical energy release rate of the rock mass; $m$ is the material constant; $l_{0}$ is the initial fault length.

When $G>R$, the fault cracks expand, and both $G$ and $R$ increase with the expansion of the fault. The main difference between the two is that $\mathrm{G}$ shows a linear positive correlation with the expansion of the fault, while the growth rate of $\mathrm{R}$ gradually decreases. If $\mathrm{G}=\mathrm{R}$, the fault stops expanding and activation. Combining formulas (2) (4) gives:

$$
\left(\frac{4 \tau_{n}^{2}+4 p^{2}}{\pi E} \pm \frac{\pi \sigma_{n}^{2}}{E}\right)^{m}\left(l_{0}+\Delta l\right)^{m}-\frac{\Delta l}{m}=G_{c}^{m}
$$

In the formula, $\Delta l$ is the activation length of the fracture crack.

Therefore, if the physical and mechanical parameters of the rock formation around the concealed fault are determined, equation (5) can be solved to obtain the vertical extension length $\Delta l$ of the concealed fault under stress. When the vertical expansion length $\Delta l$ of the concealed 
fault is greater than or equal to the thickness $\mathrm{d}$ of the effective impermeable layer, that is, $\Delta l \geqslant \mathrm{~d}$, it indicates that the concealed fault expands and develops and penetrates to the bottom water-proof layer under mining, triggering activation of the concealed fault and inducing floor outburst water. If $m=2$ is assumed, then according to formula (5), the expression of the activation length $\Delta l$ of the concealed fault in the vertical extension under the mining action can be obtained:

$$
\Delta l=\frac{1-4 D l_{0}-\sqrt{1-8 D l_{0}+16 D G_{c}^{2}}}{4 D}
$$

$$
\text { Where, } \quad D=\left[\left(4 \tau_{n}^{2}+4 p^{2}\right) / \pi E+\pi \sigma_{n}^{2} / E\right]^{2}
$$

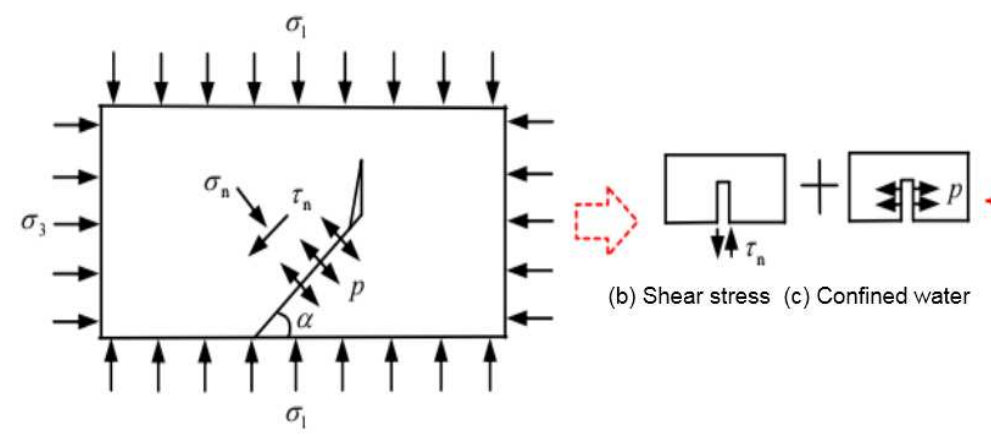

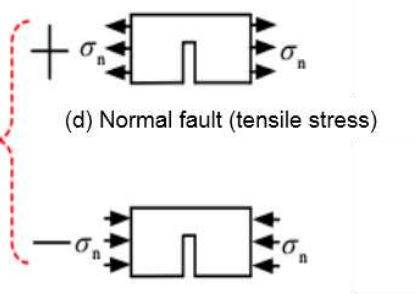

(d) Reverse fault (compressive stress)

(a)Stress state of concealed fault

Fig. 3 Factorization of the extension stress intensity of concealed faults

\section{Engineering overview}

\subsection{Fault geological conditions}

A mine in Inner Mongolia is located on the western edge of the Ordos platform. The mineable coal seams in the minefield include 12 coal-bearing layers in Shanxi Group and Taiyuan Group, with a buried depth of $380 \sim 450 \mathrm{~m}$. The strike length of the working face is $1,617 \mathrm{~m}$, and the azimuth angle is $207.5^{\circ}$. The coal seam is generally a medium-thick coal seam with an average thickness of $2.56 \mathrm{~m}$. As shown in Figure 4, the mining roadway at $290 \mathrm{~m}$ away from the cut-off position of the working face needs to pass through a normal fault with a drop of $1.4 \mathrm{~m}$. After the roadway passes through the fault zone, the stability of the surrounding rock is poor, and the local fragmentation is severe. The original support method cannot meet the normal support and production requirements, and it needs to be repaired and strengthened many times. 


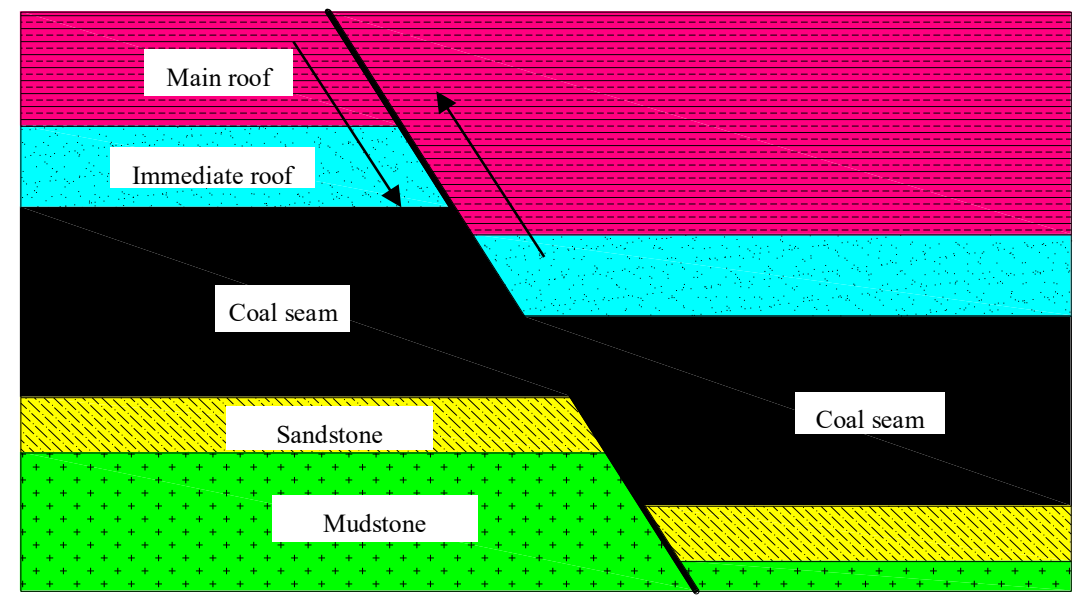

Fig. 4 fault location of working face

\subsection{Deformation characteristics of roadway}

Figure 5 (a) shows the change curve of the roof and bottom of the roadway and the two sides with the mining face. Field observations show that when the mining roadway does not cross the fault, the increase in the cumulative amount of deformation of the roof and the two sides of the roadway is small (that is, the slope of the curve $k$ is small). The deformation of the surrounding rock of the roadway tends to a stable deformation state with the mining of the working face. From the perspective of the total deformation, the displacement of the top and bottom of the roadway is greater than the displacement of the two sides of the roadway, indicating that the deformation of the top and bottom of the roadway is greater than the deformation of the two sides. When the roadway crosses the fault location, the deformation of the roof and floor and the two sides of the roadway changes obviously, and the curve slope $k_{2}$ is obviously greater than $k_{1}$ at this time. Especially when the stoping roadway is $20 \mathrm{~m}$ away from the measuring point (within the fractured zone of the fault), under the original support conditions, the convergence value of the roof and bottom of the roadway and the displacement of the two sides have reached the maximum value, respectively $231.5 \mathrm{~mm}$ and $364.0 \mathrm{~mm}$. The malignant expansion of the large deformation of the roadway has exceeded the maximum extension length of the glass fiber reinforced plastic bolts used for the support, resulting in the failure of many bolts in the roadway near the working face, and the coal wall of the roadway is smashed and the roof is serious ${ }^{[10]}$.

Figure 5(b) shows the stress change law of the top and bottom plates and the two sides. With the continuous advancement of mining at the working face, the bolt-bearing load generally shows an increasing dynamic trend; At a position $60 \mathrm{~m}$ away from the front of No. 4 station, due to the 
$181 \mathrm{MPa}$ at $30 \mathrm{~m}(90 \mathrm{~m}$ in the figure) in front of the fault; and as the working face crossed the fault $10 \mathrm{~m}$ 182 (At 50m) in the figure, the roof pressure gradually releases, at this time the concentrated stress of 183 the roadway decreases to the minimum value of $1.008 \mathrm{MPa}$; and when the working face is mined 184 within $50 \mathrm{~m}$ of the No. 4 station, the roof pressure begins to increase again. Therefore, the fault 185 structure leads to changes in the direction and magnitude of the initial principal stress field of the 186 surrounding rock of the roadway in the mining face. The local stress of the roadway accumulates 187 unevenly, resulting in uneven large-scale deformation of the roadway. At the same time, during the 188 forward advancement of the working face, the closer the distance to the fault is, the significantly 189 increased supporting pressure in the front unmined coal body appears.

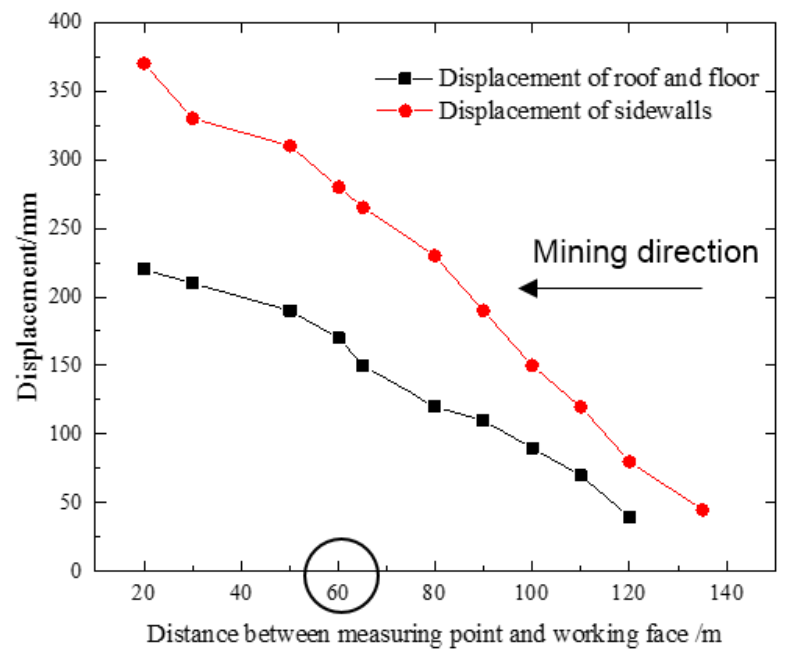




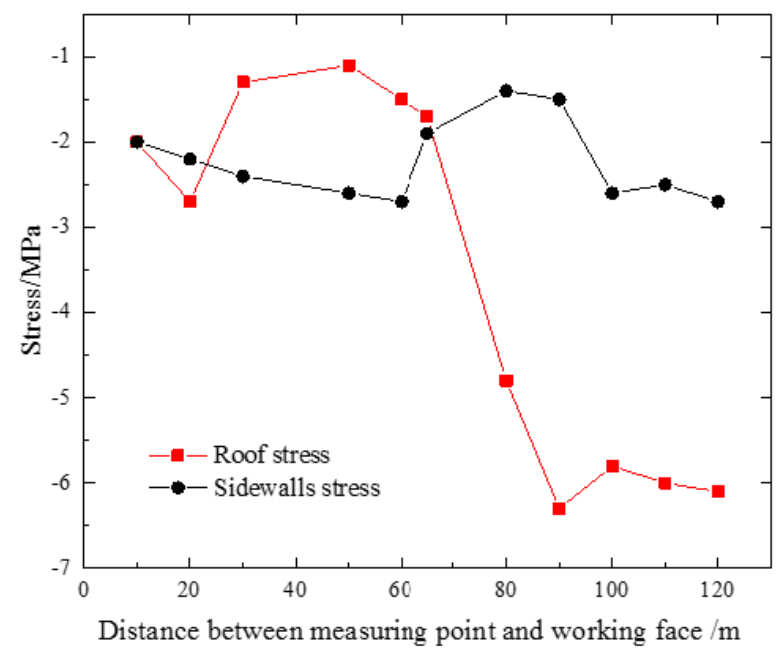

192

(b)

Fig. 5 change curve of field measurement points with mining of working face: (a) displacement; (b) stress

Figure 6 is a peep view of typical surrounding rock boreholes under the influence of fault structure in the track roadway at 5302 working face of Zhaolou Coal Mine, a kilometer deep mine. It can be observed that the surrounding rock fragmentation can be divided into severe, medium, and minor damage zones from the inside to the outside. When the roadway crosses a fault or structural zone, the surrounding rock fragmentation range is relatively large, the range of the minor damage zone can reach $4.88 \mathrm{~m}$, the range of the medium damage zone is $3.70 \mathrm{~m}$, and the range of the severe damage zone is $2.28 \mathrm{~m}$. Therefore, the failure area is mainly distributed around the plastic zone of the roadway, and in the fault fracture zone, the degree of broken surrounding rock shows irregular expansion and development, specifically the character- istics of left side $>$ right side $>$ roof $f^{[22]}$. 


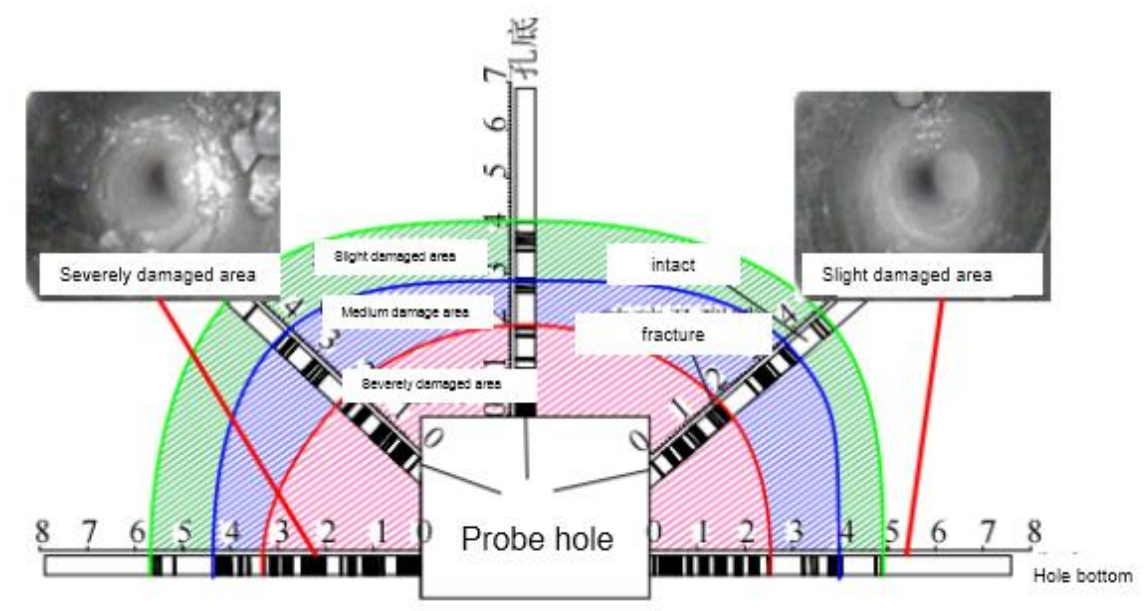

205

206

207

208

209

210

211

212

213

214

215

216

217

218

219

220

221

222

223

224

Fig. 6 Drilling in broken surrounding rock of typical fault passing roadway

\section{Numerical model experimental research}

\subsection{Model establishment}

In order to better study the damage of the roadway through the fault and the support effect, this section uses the Flac ${ }^{3 \mathrm{D}}$ numerical software to establish a corresponding numeri- cal model to conduct a finite element simulation analysis on the actual roadway through the fault. According to the engineer- ing geological conditions of the site, the site conditions are appropriately simplified, and the complete rock tunnel model before the fault is processed as follows ${ }^{[23,24]}$ : (1) Ignore the weight of the rock mass; (2) The surrounding rock of the roadway is regarded as a continuous and isotropic material; (3) The mechanics of the surrounding rock of the roadway is treated as a plane strain problem. The model of the roadway crossing the fault fracture zone is similar to the modeling process of the complete rock roadway. Due to the existence of the fault structure, the surrounding rock of the roadway is in a relatively broken state ${ }^{[3]}$. Therefore, the rock parameters other than the coal seam are assigned to the fracture zone rock parameters

for the stability analysis of roadway fault. The numerical model is built with a size of $50 \times 50 \times 20 \mathrm{~m}$, with a total of 60,291 nodes and 55,360 units. The specific rock mechanics calculation parameters are shown in Table 2Table 2 Mechanical calculation parameters of each stratum

\begin{tabular}{llllllllll}
\hline \multirow{2}{*}{$\begin{array}{l}\text { Number } \\
\text { Surrounding }\end{array}$} & Rock & Bulk density & Uniaxial & Uniaxial & Cohesion & Internal & Elastic & Poisson's \\
& Rock (from & thickness & $\gamma / \mathrm{g}_{\mathrm{cm}} \mathrm{cm}^{-3}$ & compressive & tensile & $C / \mathrm{MPa}$ & friction & Modulus & ratio $\mu$ \\
\hline
\end{tabular}




\begin{tabular}{cccccccccc}
\hline 1 & Sandy shale & 13.44 & 2.71 & 78 & 2.04 & 16.73 & 37 & 2.29 & 0.45 \\
2 & Fine & 8.74 & 2.54 & 65 & 1.03 & 13.21 & 26 & 1.42 & 0.21 \\
3 & Siltstone & 5.24 & 2.67 & 40 & 1.80 & 18.69 & 32 & 1.65 & 0.22 \\
4 & Clay & 1.54 & 2.48 & 14 & 1.12 & 12.55 & 31 & 0.38 & 0.16 \\
5 & Coal seam & 9.17 & 1.37 & 12 & 1.43 & 10.60 & 29 & 0.45 & 0.19 \\
6 & Limestone & 4.60 & 2.60 & 28 & 2.07 & 25.30 & 35 & 1.05 & 0.22 \\
7 & Siltstone, & 7.17 & 2.50 & 39 & 2.99 & 26.40 & 35 & 1.23 & 0.19 \\
8 & Medium & 10.69 & 2.40 & 36 & 2.91 & 13.31 & 31 & 1.24 & 0.24 \\
9 & Fault zone & 1.50 & 0.98 & 1.15 & 0.08 & 0.02 & 10 & 0.20 & 0.44 \\
\hline
\end{tabular}

The cross section of the on-site roadway is a trapezoidal roadway, with a width of $4.6 \mathrm{~m}, 4.45$

$226 \mathrm{~m}$ on the left side and $3.3 \mathrm{~m}$ on the right side. The original support scheme is a combined support 227 of bolts and cables, as shown in Figure 7. Among them, the diameter of the anchor rod is $\phi 22 \times$ $2282400 \mathrm{~mm}$, and the distance between rows is $700 \times 600 \mathrm{~mm}$; the anchor cable is $\phi 22 \times 7300 \mathrm{~mm}$ in 229 diameter and the distance between rows is $1600 \times 800 \mathrm{~mm}$. In addition, in the numerical process, a 230 measuring point is set on the top and bottom plates and the two sides to monitor the convergence 231 of each part of the roadway.

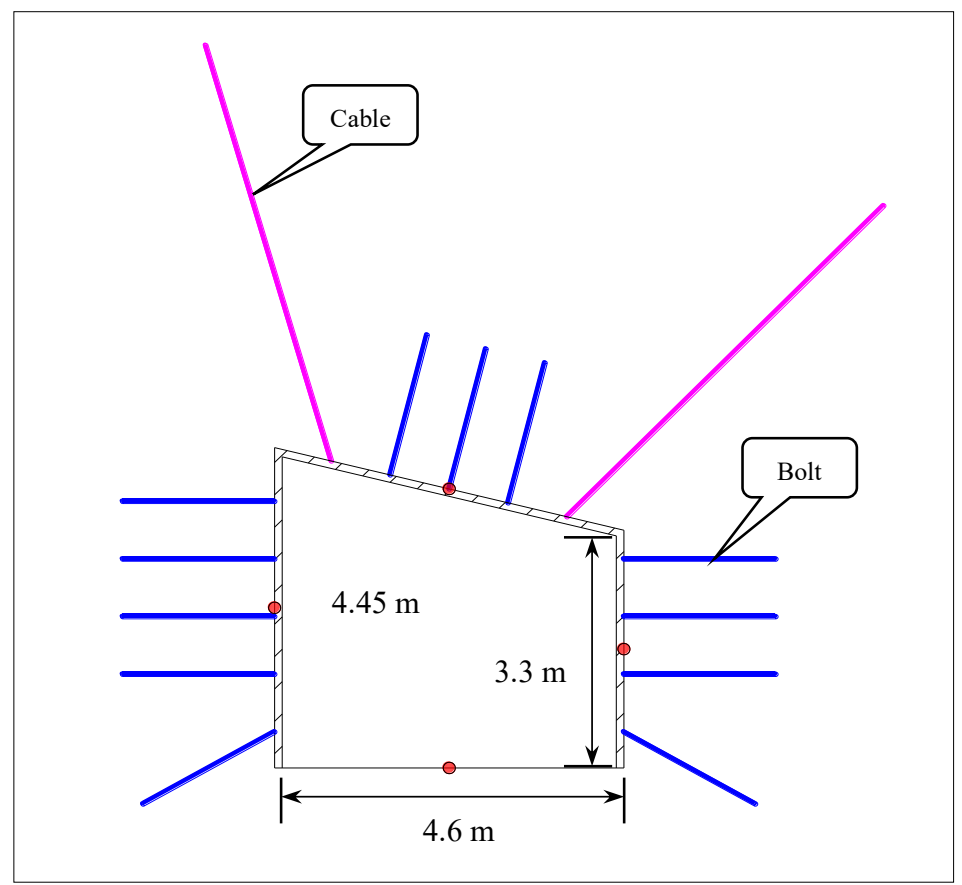

Fig. 7 support structure and inspection point layout 


\subsection{Deformation characteristics of roadway before crossing the fault}

Figure 8 shows the support plastic zone, total displacement contour cloud map and monitoring point convergence before the roadway crosses the fault. It can be found that before the roadway crosses the fault, the original support scheme can better support and stabilize the deformation of the surrounding rock, and the total deformation of the roadway is small (the deformation of the roof and floor does not exceed $250 \mathrm{~mm}$ ). Judging from the distribution of the plastic zone, the distribution range of the plastic zone of the surrounding rock of the roadway is also small, and the original support scheme has a better coordination and stability effect on the complete surrounding rock.

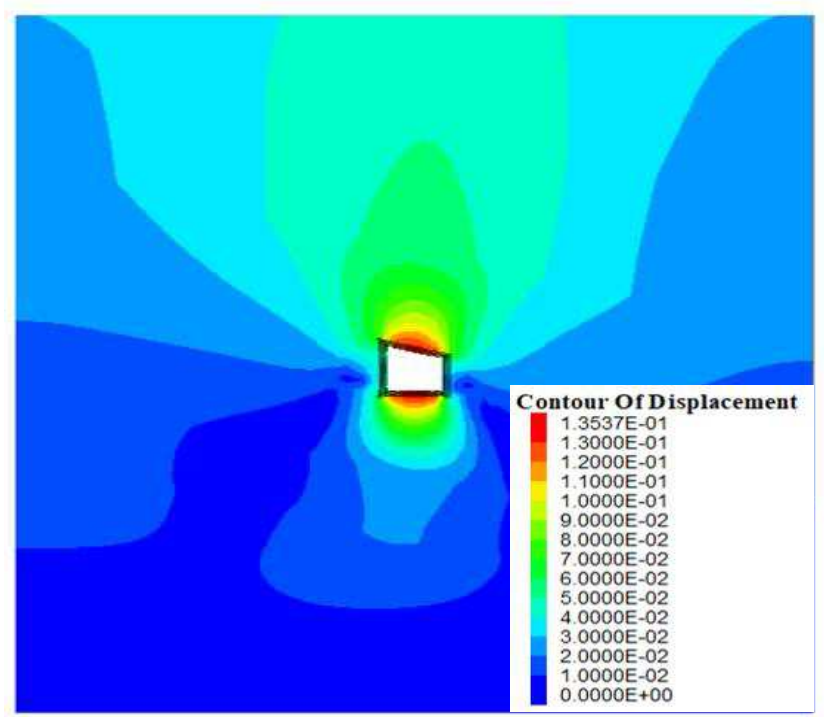




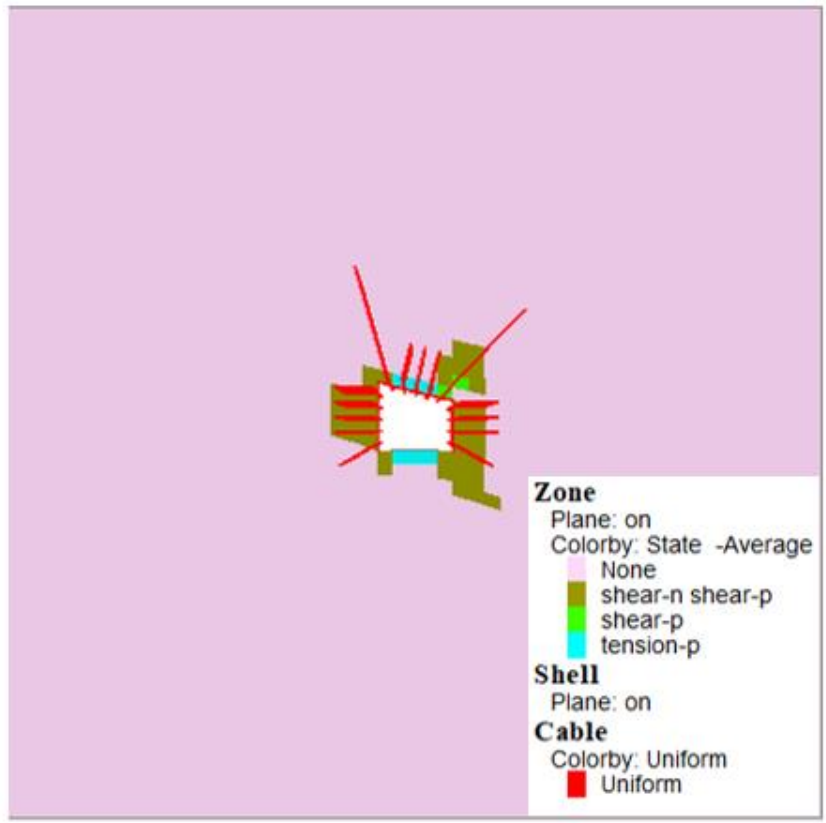

(b)

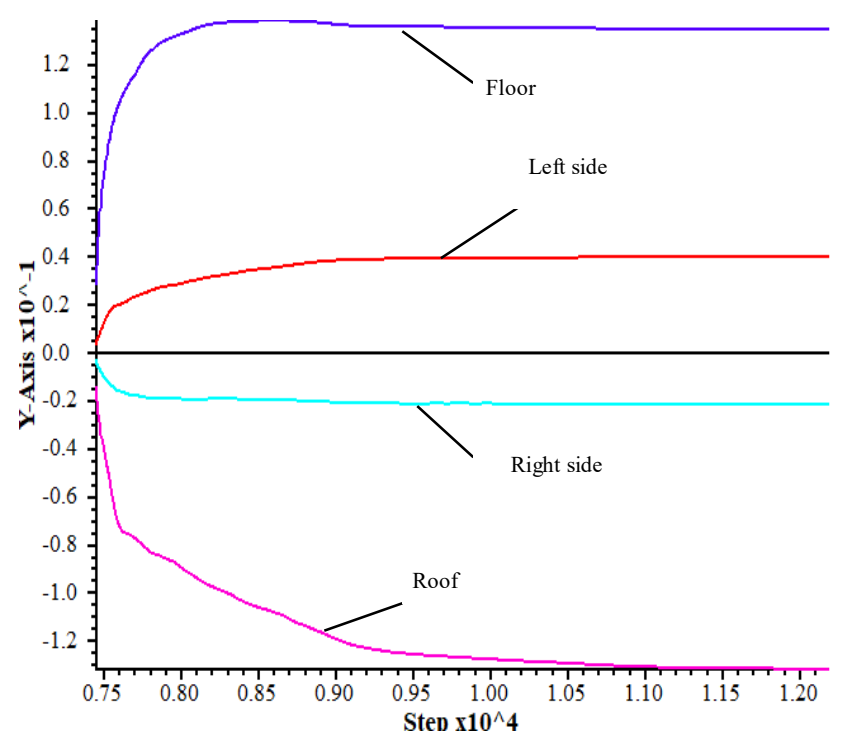

(c)

Fig. 8 deformation of roadway before passing through fault: (a) plastic area; (b) isoline cloud chart of total

When the roadway passes through the fault, the rock mass is severely broken and the stress changes greatly. As shown in Figure 9, the plastic zone of the roadway crossing the fault has obvious malignant expansion, presenting a similar "butterfly" plastic zone range. Large deformation failure occurs in the mining roadway, the essence of which is that the stress failure zone of the roadway is irregular, and the support means cannot control the malignant development 
of the plastic zone, es- pecially for the "butterfly" failure theory ${ }^{[25-26]}$. The original support plan of the roadway was within the "butterfly" plastic zone, and the support structure failed. The original support method cannot maintain the stability of the roadway well at this time, the uneven deformation of the surrounding rock of the roadway continues to increase, the full section of the roadway shrinks seriously, and the displacement convergence of the roof and floor and the two sides can reach nearly $6,000 \mathrm{~mm}$.
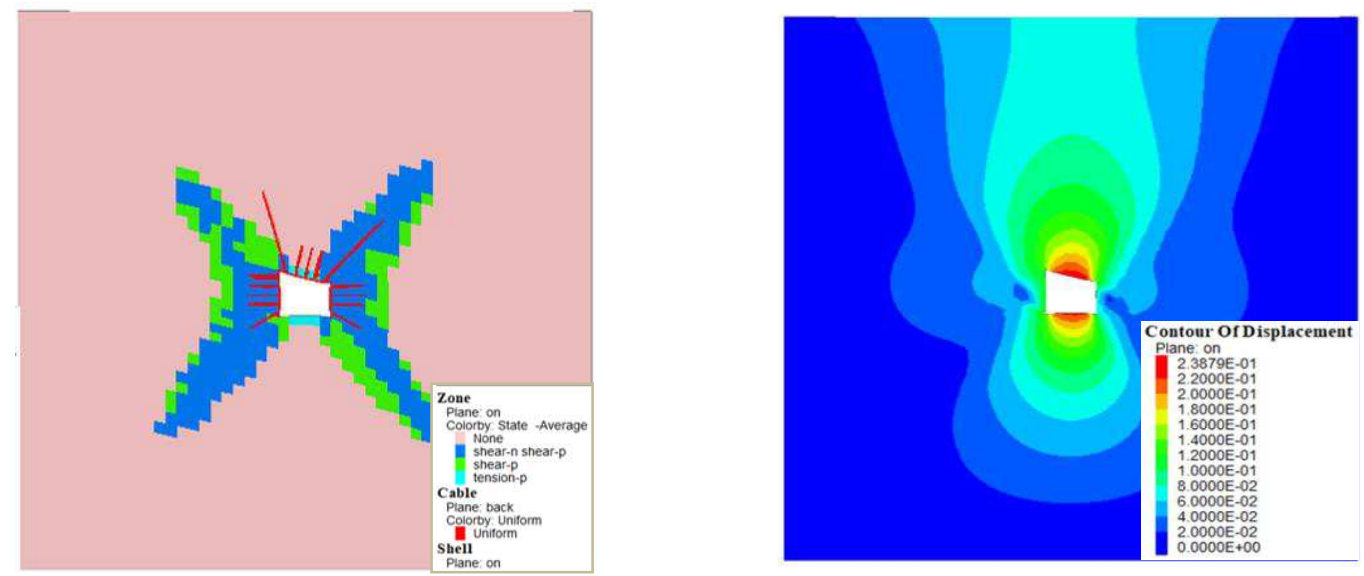

(b)

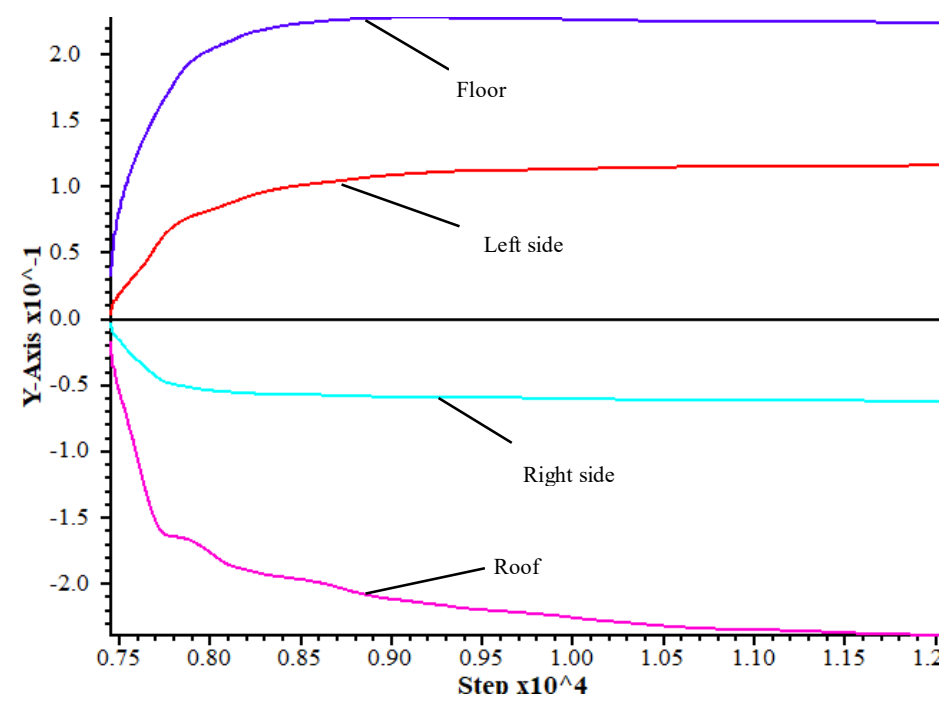

(c)

Fig. 9 numerical calculation results of roadway passing through fault: (a) plastic area after original

The control countermeasures and support principles for the main fault-crossing and large-deformation roadways are as follows: 
Using high-pressure grouting, after being squeezed or permeated in the criss-cross cracks of the surrounding rock of the roadway, an interconnected network skeleton structure is formed in the cracked rock mass of the surrounding rock. Improve the overall mechanical properties of the damaged surrounding rock of the roadway, reduce the permeability of the rock formation, improve its self-bearing strength and long-term surrounding rock stability.

2) Multiple support in stages

(1) Reserve the maximum possible deform- ation space of the roadway; (2) The primary support allows a certain amount of surround- ing rock deformation and can release the high and residual stresses in the surrounding rock; (3) The secondary support mainly controls the long-term engineering rheology of the surrounding rock .

Generally speaking, in addition to the impact of the stress disturbance on the roadway, the more important thing is that the

roadway is broken, which reduces the integrity of the surrounding rock, and the support system and the surrounding rock cannot jointly bear the broken deformation of the surrounding rock. In order to better control the deformation and failure of extremely broken surrounding rocks when such roadways pass through faults, according to the numerical calculation results, in order to reduce the extent of the roadway plastic zone, the emphasis is on strengthening the corners of the roadway "butterfly" zone. Therefore, comprehensively considering the characterist- ics of the plastic zone of the fault-broken roadway, a joint optimization support scheme considering the strengthening of the roadway angle is proposed: when the roadway crosses the fault, the roadway angle is densified or the bolts and cables are lengthened; for special fractures The surrounding rock of the roadway considers strengthening the support, and cooperates with the grouting reinforcement, the partial damage is serious, and the full-section support reinforcement is carried out.

Figure 10 shows the numerical calculation results of the reinforced support scheme for the roadway crossing the fault. It can be found that after the roadway plastic zone is strengthened, the "butterfly" plastic zone area is reduced, and the anchor cables and bolts are outside the plastic zone. The malignant development of the plastic zone is well controlled. The long-term displacement of the surrounding rock of the roadway has been well controlled (when the calculation reaches 12,000 steps, the distance between the two sides of the roadway does not 
304 from the maximum shear stress diagram, the concentrated stress around the roadway is also 305 relatively small. Therefore, the proposed "bolt, anchor cable, grouting" combined support scheme 306 has good stability for the support of extremely broken roadways through faults, and ensures the stability and long-term use of the roadways.

308

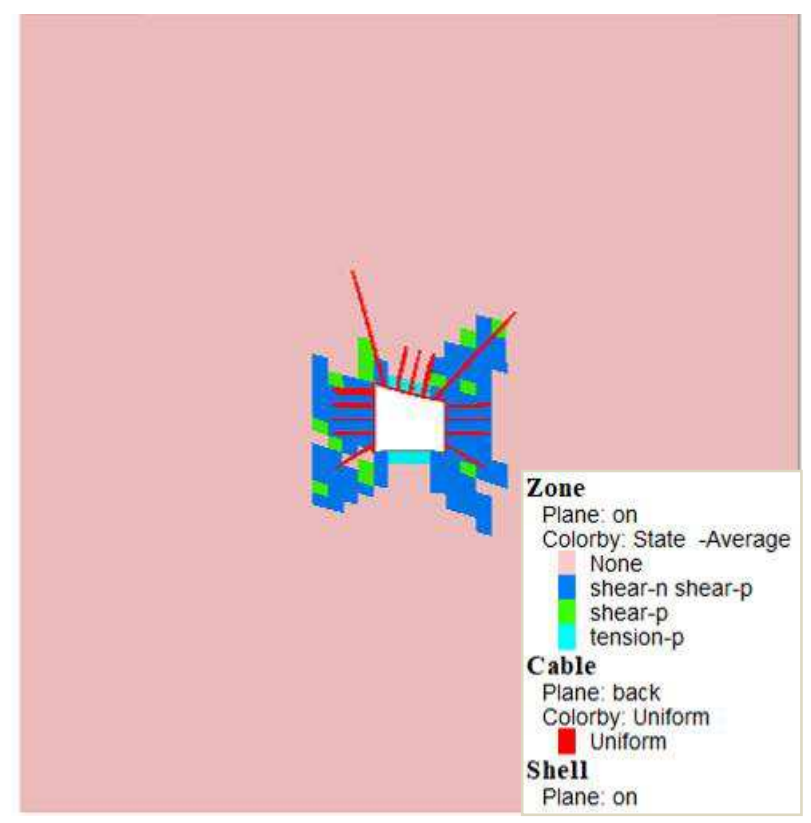

(a)

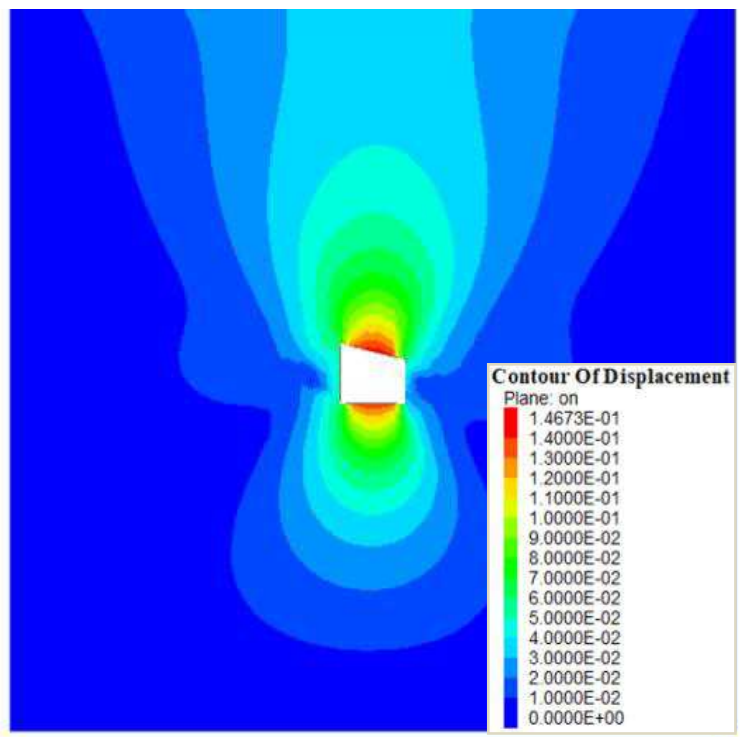



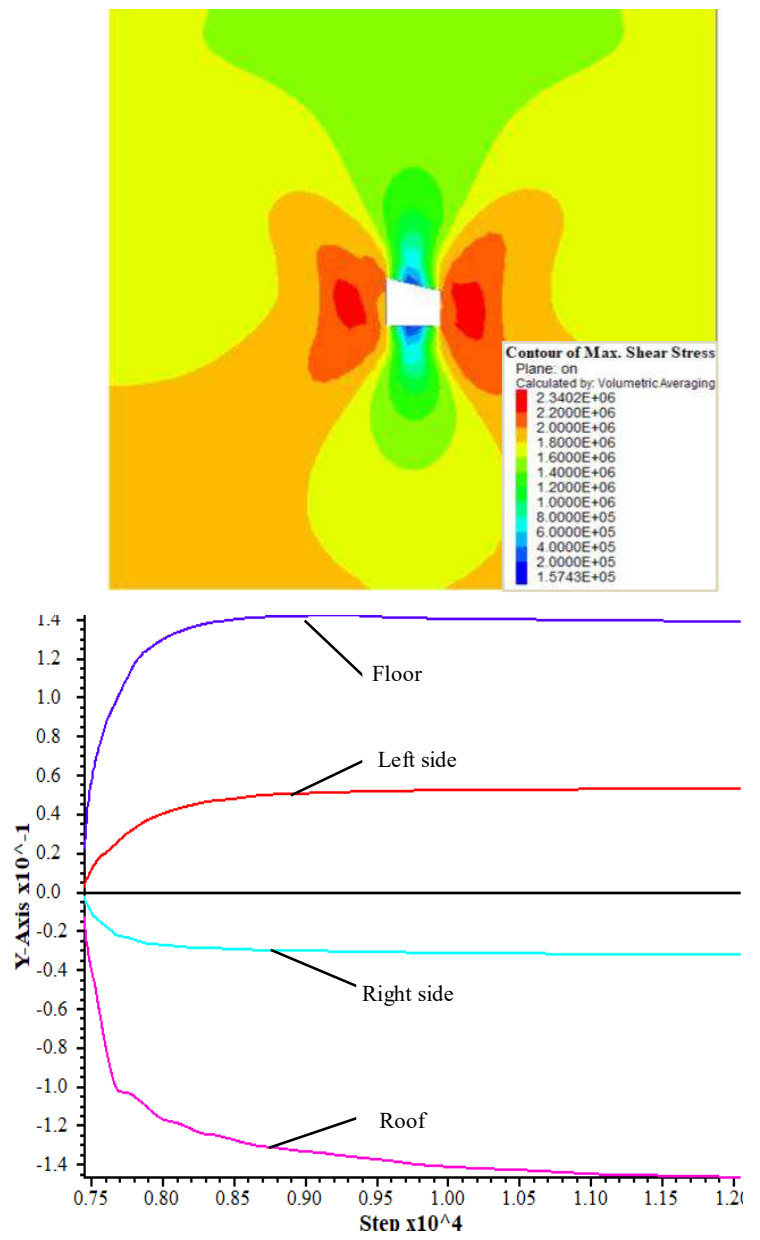

Fig. 10 Numerical calculation results of the optimal support scheme for roadway passing through faults: (a)

points

\section{Conclusions}

(1) The mechanical characteristics and failure characteristics of the fault fracture zone are summarized, and the mining activation mechanism of concealed small faults and small structures is explored through fracture mechanics theory, and the critical value of water inrush due to floor failure caused by fault activation is obtained.

(2) The fault fracture zone has the characteristics of plastic faults, resembling a "butterfly" distribution. The internal structure of the rock mass is obviously different, and the mechanical unity of the rock formation is reduced within a certain range.

(3) The roadway crosses the fault and the rock is broken, the main stress state and the direction of the stress field change, showing large deformation and long-term rheological failure. 
The original supporting structure cannot maintain the stability of the surrounding rock of the roadway, and its supporting capacity cannot be increased to the maximum Good support effect.

(4) Summarized the principles and key points of the support control of the fault-crossing roadway. By analyzing the expansion form of the "butterfly" plastic zone in the roadway corners of the fault-crossing section under the original plan, the "bolt + anchor cable + anchor" "Grouting" is the main optimization support scheme. The numerical results show that the convergent deformation of the surrounding rock of the roadway under this scheme gradually stabilizes, the final convergence value is small, the stress distribu- tion is uniform, and the support anchor cables are anchored into the stable deep rock. The overall stability of the roadway section crossing the fault is guaranteed.

\section{Acknowledgments}

Conflict of interest All the authors in this paper declare that they have no conflict of interest.

\section{References}

This study was financially supported by the Research Project of Guangxi Vocational Education And Teaching Reform in 2020 (Project No.GXGZJG2020B150) Research and Practice on training Mode of Innovative Talents in Engineering Management Specialty based on engineering practice Ability. Research Project of Guangxi Higher Education Undergraduate Teaching Reform in 2019 (Project No.2019JGA333). The authors would also like to express appreciation to the reviewers and editor for their valuable comments and suggestions that helped improve the quality of our paper.

\section{Data Availability}

The data used to support the findings of this study are available from the corresponding authors upon request.

\section{Compliance with Ethical Standards}

[1] CHAO Jianwei, YU Tongyong, WEI Sijiang. Research on failure characteristics of mining 
roadway through fault roof . Mining Safety and Environmental Protection,2009,36(02):13-15+92.

[2] GAO Mingzhong, HAN Lei, GAO Xinya. Study on the control technology of surrounding rock through fault in roadway group . Journal of Anhui University of Science and Technology (Natural Science Edition), 2010(03):21-26.

[3] Gao Yubing, Wang Jiong, Gao Hainan, Yang Jun, Zhang Yong, He Manchao. Influence of fault structure on pressure law and surrounding rock control of automatic roadway forming under cut roof pressure relief . Chinese Journal of Rock Mechanics and Engineering,2019,38(11):2182-2193.

[4] Gao Kui, Liu Zegong, Liu Jian, Zhu Feihao, Qiao Guodong, Zhang Shuchuan. Application of directional shaped charge blasting to weaken reverse fault in comprehensive excavation face . Chinese Journal of Rock Mechanics and Engineering,2019,38(07):1408-1419.

[5] YU Weijian, GAO Qian, JIN Xueqi, et al.In-situ investigation and mechanical characteristics analysis of deep rock mass influenced by fault tectonics . Progress in Geophysics, 2013(01):494-503.

[6] GUO Wenbing, DENG Kazhong, BAI Yunfeng. Study on the law of surface movement affected by faults . Journal of Liaoning Technical University (Natural Science Edition), 2002(06):26-28.

[7] PAN Yishan, WANG Laigui, ZHANG Mengtao, et al.Theoretical and experimental study on the occurrence of fault rock burst . Chinese Journal of Rock Mechanics and Engineering, 1998, 17(06):642-642.

[8] Pan Yue, Xie Jinyu, Gu Shanfa. Theoretical analysis of sudden change of mine fault rock burst under non-uniform confining pressure . Chinese Journal of Rock Mechanics and Engineering, 2001, 20(3).

[9] ZHANG Mingqiang. Design and Practice Analysis of Roadway Support Scheme over Fault . Inner Mongolia Coal Economy, 2019(13).

[10] MENG Zhaoping, PENG Suping, LI Hong. Changes in physical and mechanical properties of coal near normal faults and their effects on coal pressure distribution . Journal of China Coal Society, 2001(06):3-8.

[11] Wu Qiang. Design and optimization of roadway support for fractured rock mass in an underground mine . Modern mining,2019,35(08):225-229.

[12] Jiang Yaodong, Lu Yukai, Zhao Yixin, Gao Zhanxue. Multi-parameter Monitoring of Stability of Roadway Through Fault in Fully Mechanized Mining Face . Journal of China Coal Society (10):1601-1606. 
[13] Wang Qi, Li Shucai, Li Zhi, Li Weiteng, Wang Fuqi, Jiang Bei, Wang Dechao, Wang Hongtao. Rock and Soil Mechanics,2012,33(10):3093-3102.

[14] Xiao Tongqiang, Bai Jianbiao, Li Jinpeng, Wang Xiangyu, Yan Shuai. Journal of Mining and Safety Engineering,2010,27(04):482-486.

[15] Cheng A.G,Ning S.Z,Yuan T.X.Resarch on compresensive regionalization of China coal resources.China Coal Geology,2011,23(8):5-8.

[16] XIE Yanshi, TAN Kaixuan. Fractal study of fault structure and its geological application . Geology and Geochemistry,2002:30-31.

[17] JIANG Jinquan et al. Stability and Control Design of Roadway Surrounding Rock Structure [M]. Coal Industry Press,1999:25-27.

[18] ZHANG Xiangdong, YIN Zengguang, PENG Wei, et al.Reinforcement and support technology of soft rock roadway crossing fault fracture zone in Hongqingliang Coal Mine . Metal Mine, 2017(9):60-65.

[19] HU Guodong. Study on Stability Influence and Control Technology of Roadway Surrounding Rock near Fault [D]. China University of Mining and Technology,2019.

[20] SUN Yunjiang, ZUO Jianping, LI Yubao, et al. Microseismic monitoring and water inrush mechanism analysis of water conducting fracture zone in deep pressure mining of Xingdong mine . Rock and Soil Mechanics,2017,38(08):2335-2342.

[21] Li Zhengneng. Applied Fracture Mechanics [M]. Beijing: Beijing University of Aeronautics and Astronautics Press, 2012. (in Chinese)

[22] Yu Weijian, Wu Genshui, Yuan Chao, Wang Ping, Du Shaohua. Failure characteristics and engineering stability control of roadway surrounding rock based on partial stress field . Journal of China Coal Society,2017,42(06):1408-1419.

[23] WANG Qi, XU Yingdong, XU Shuo, et al. Journal of Mining and Safety Engineering,2019,36(05):916-923. (in Chinese)

[24] Du Shaohua, Yu Weijian, Zhang Tianlian, Zhao Jianfeng. Deformation mechanism and support technology of coal rock roadway with weak and large deformation in extreme crushing . Coal Science and Technology,2016,44(12):15-21+56.

[25] Zhiqiang Zhao, Nianjie Ma, Xiaofi Guo, Xidong Zhao, Long Fan. Mechanism and Control of Butterfly Blade Caving in Large Deformation Mining Roadway. Journal of China Coal 
417 Society,2016,41(12):2932-2939.

418 [26] Nianjie Ma, Xiaofi Guo, Zhiqiang Zhao, Xidong Zhao, Hongtao Liu. Mechanism and criterion of 419 butterfly rock burst in homogeneous circular roadway . Journal of China Coal $420 \quad$ Society,2016,41(11):2679-2688.

421 
From the fracture center to the driving plate side

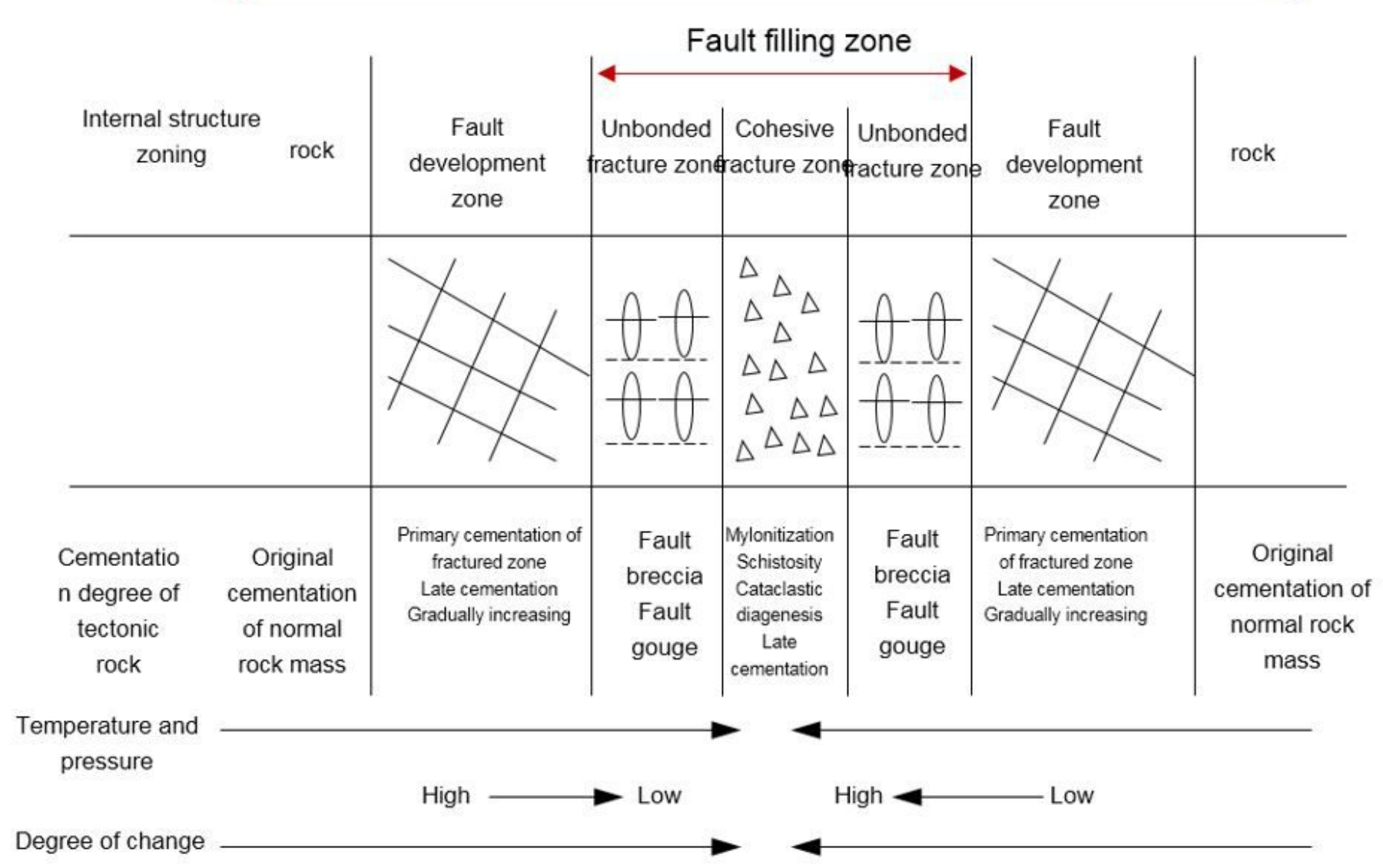

\section{Figure 1}

Characteristics of zoning in fault zone.
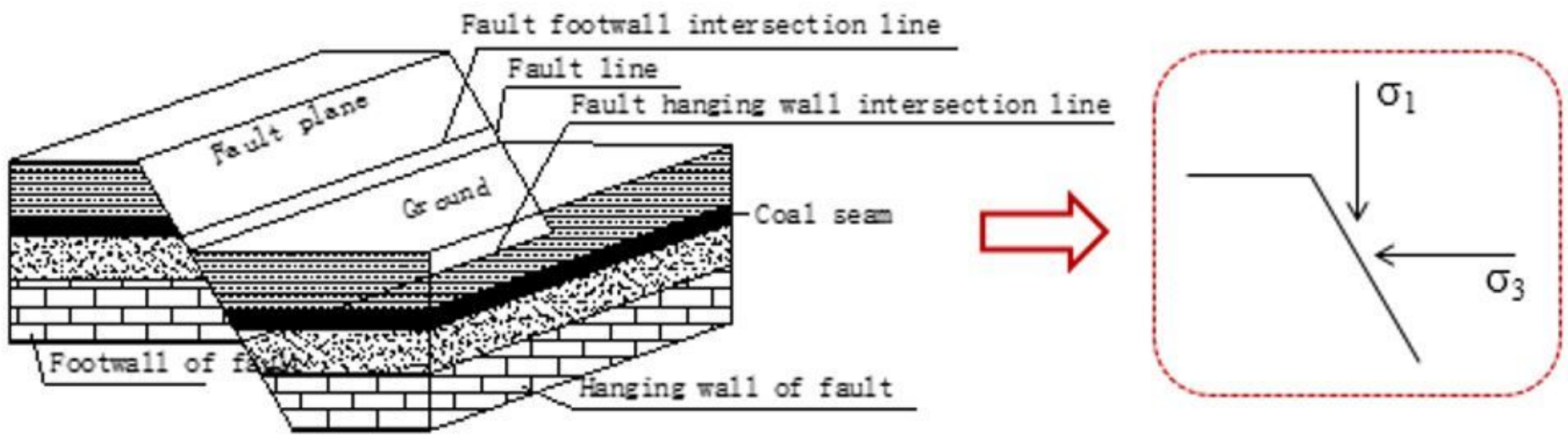
Figure 2

Schematic diagram of coal bearing normal fault
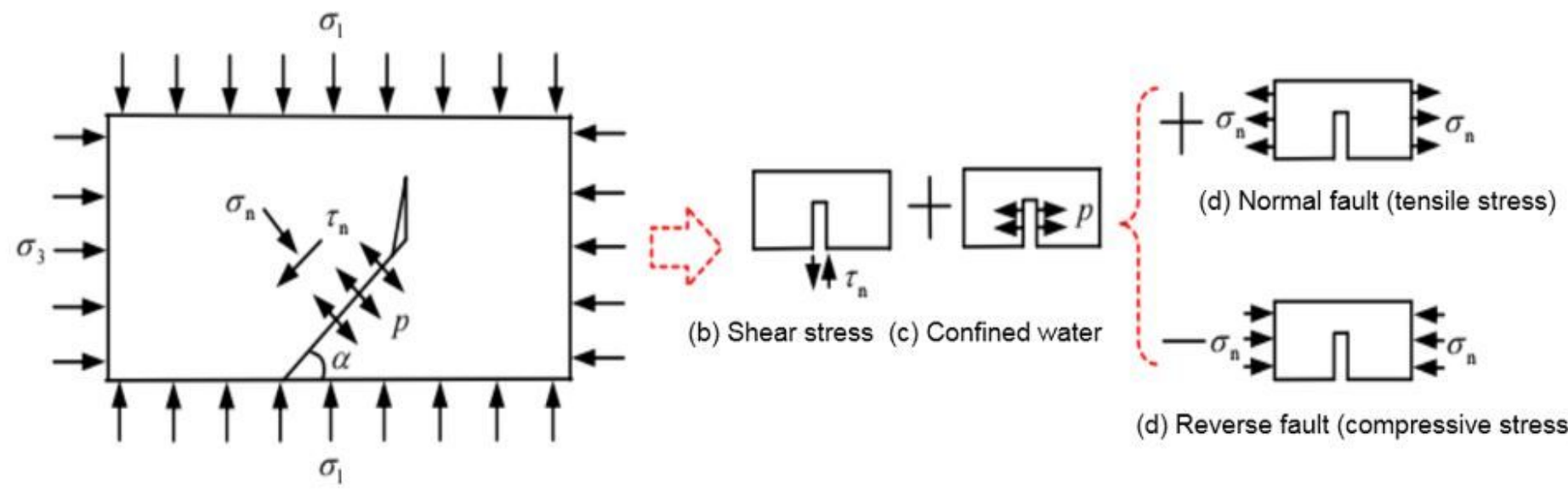

(d) Reverse fault (compressive stress)

(a)Stress state of concealed fault

Figure 3

Factorization of the extension stress intensity of concealed faults

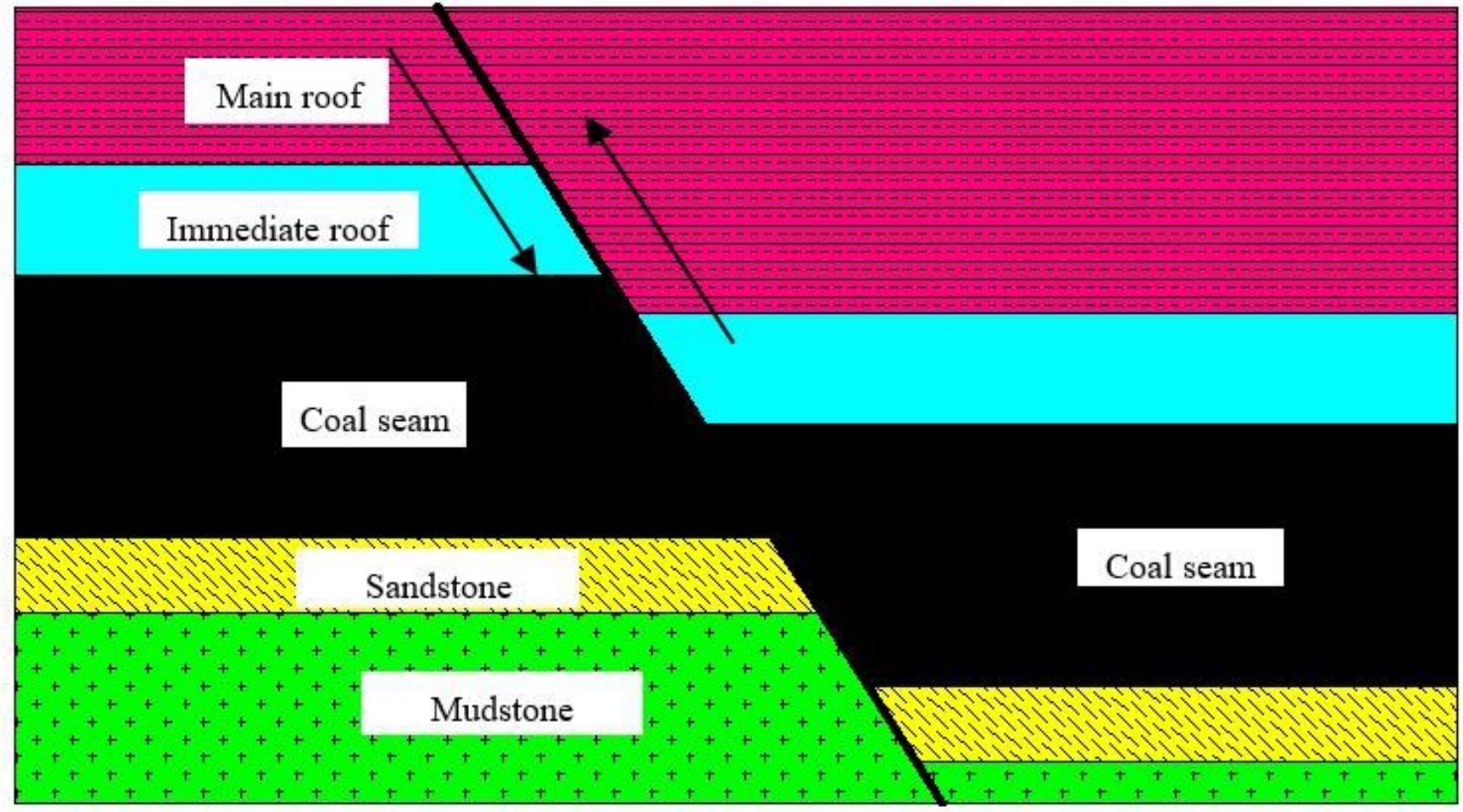

Figure 4

fault location of working face 


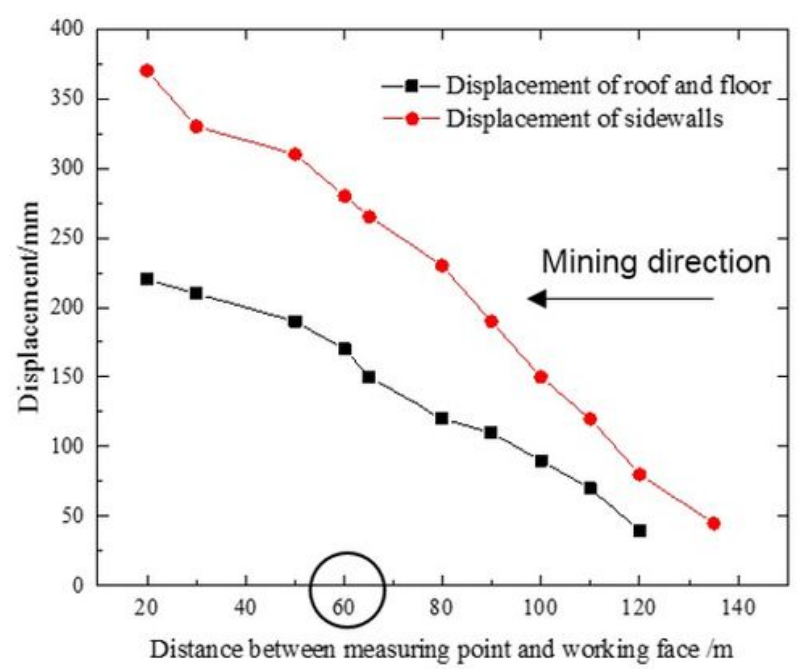

(a)

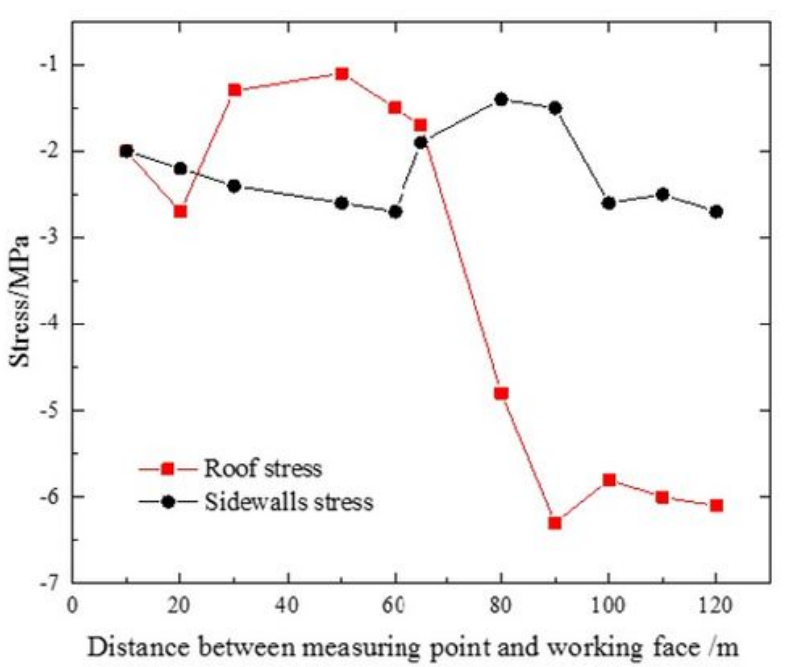

(b)

\section{Figure 5}

change curve of field measurement points with mining of working face: (a) displacement; (b) stress

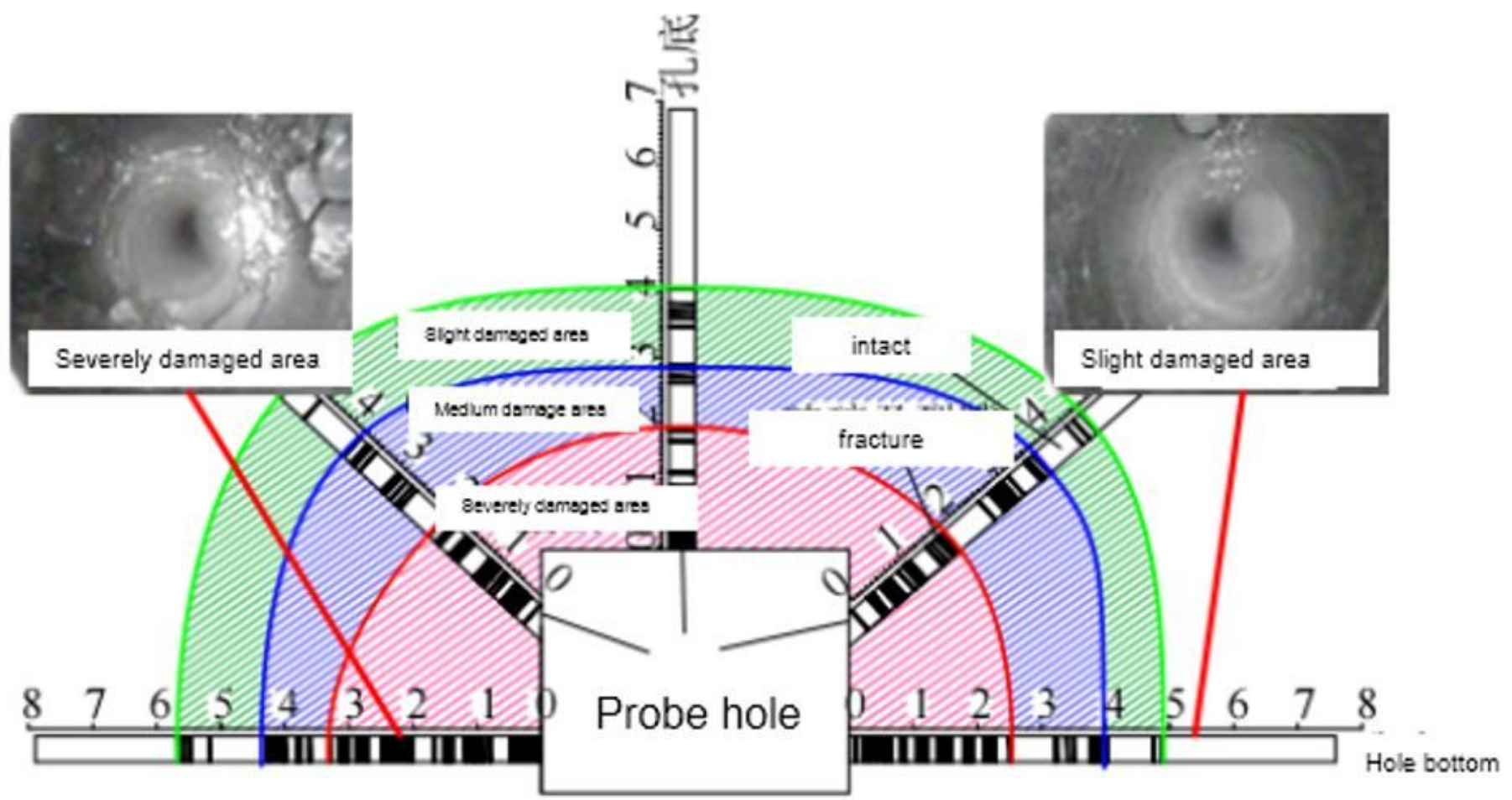


Figure 6

Drilling in broken surrounding rock of typical fault passing roadway

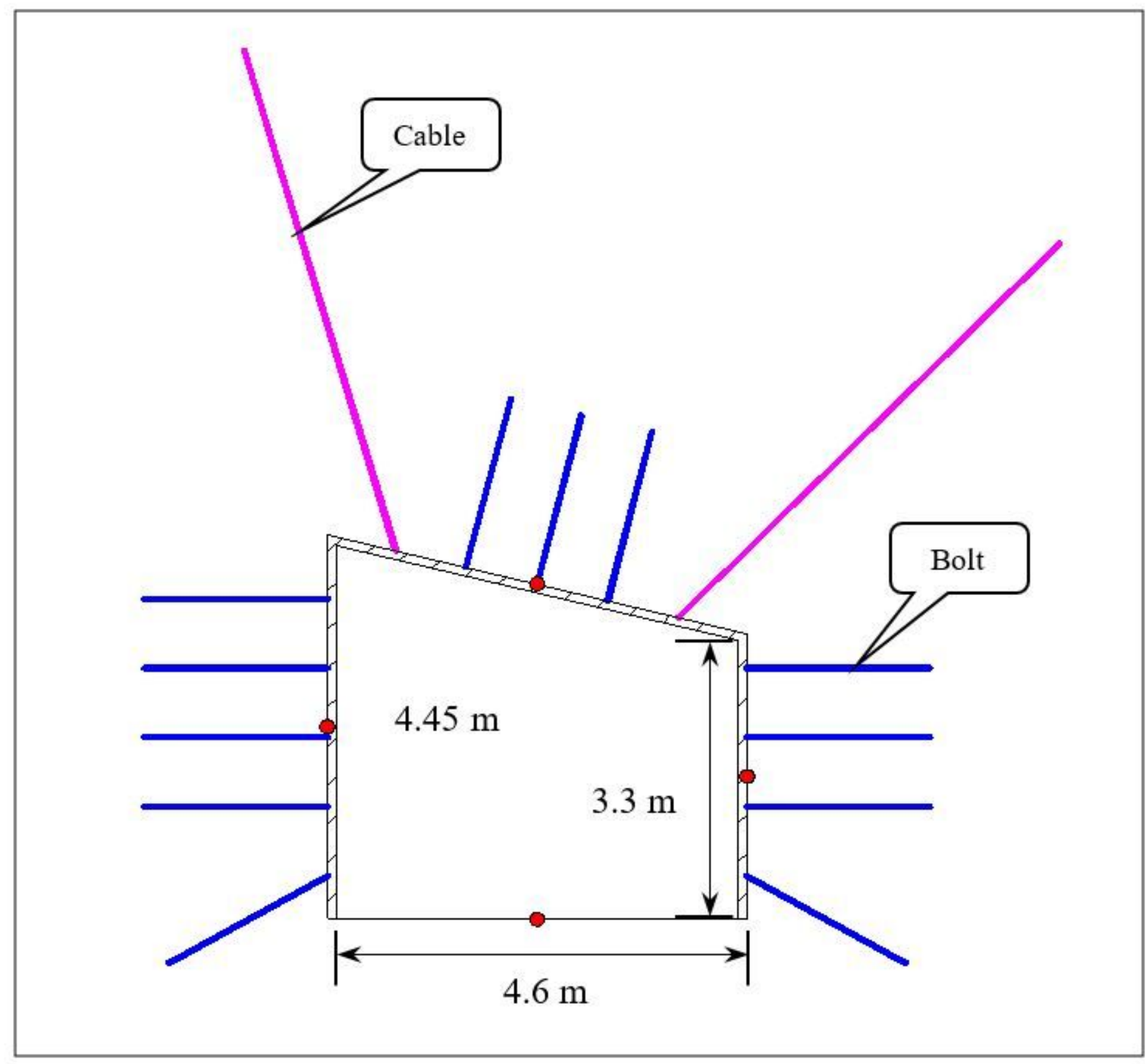

Figure 7

support structure and inspection point layout 


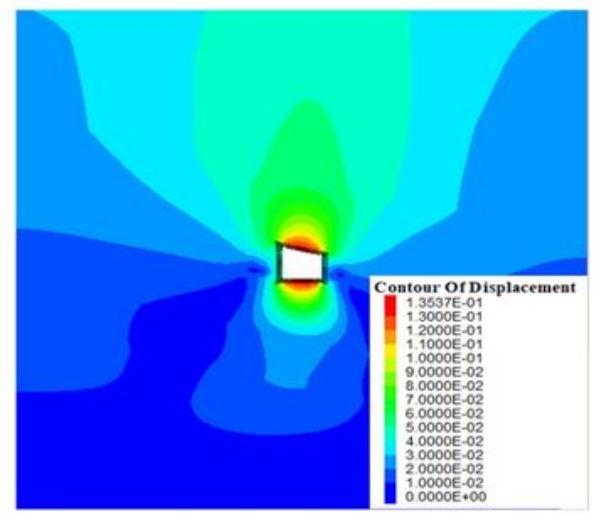

(a)

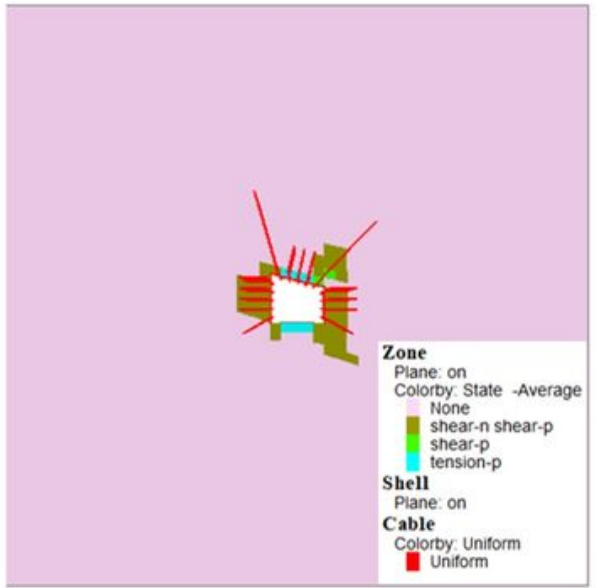

(b)

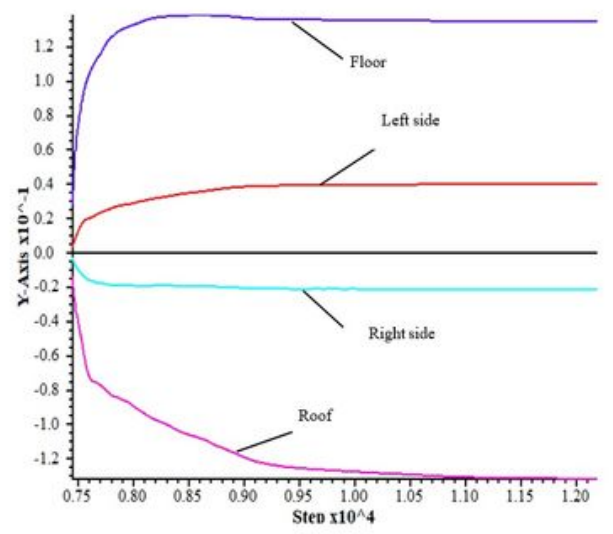

(c)

\section{Figure 8}

deformation of roadway before passing through fault: (a) plastic area; (b) isoline cloud chart of total displacement; (c) convergence curve of monitoring point 


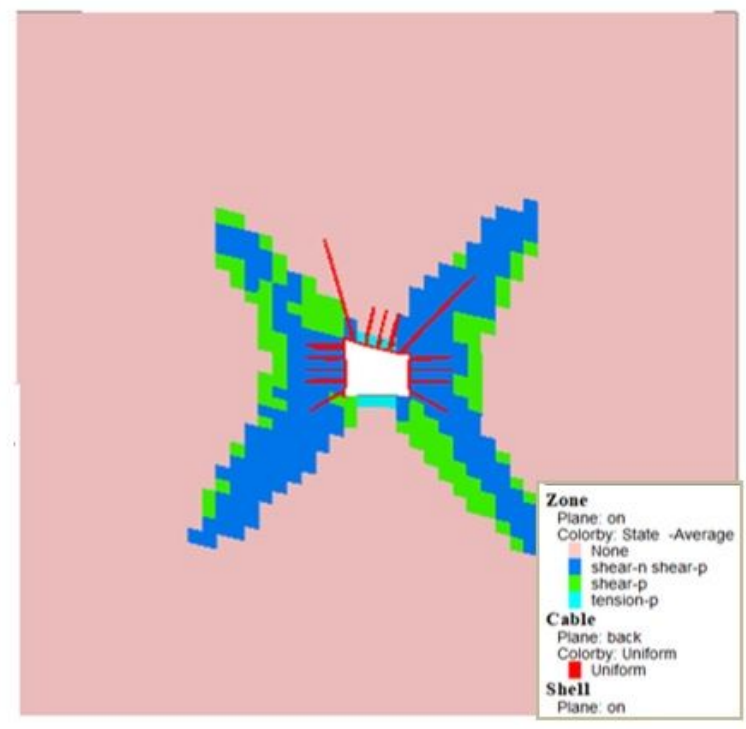

(a)

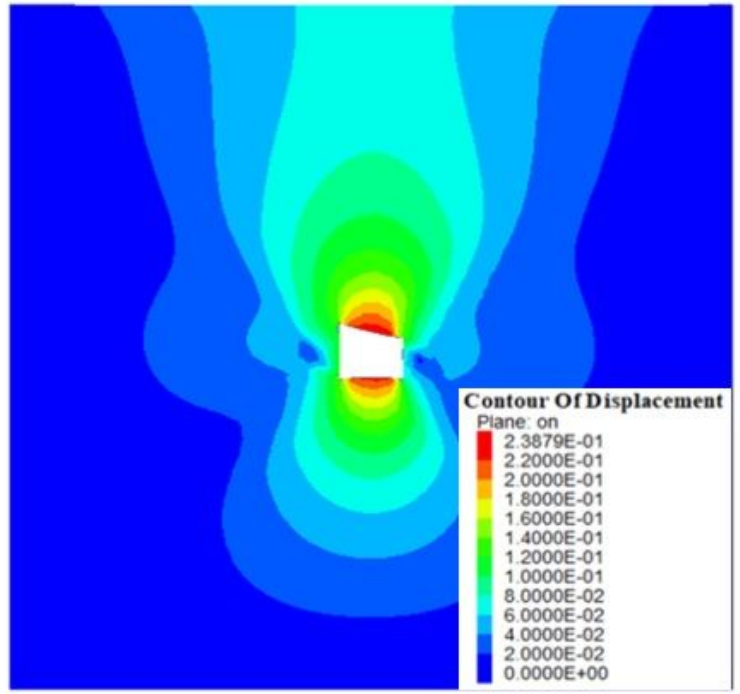

(b)

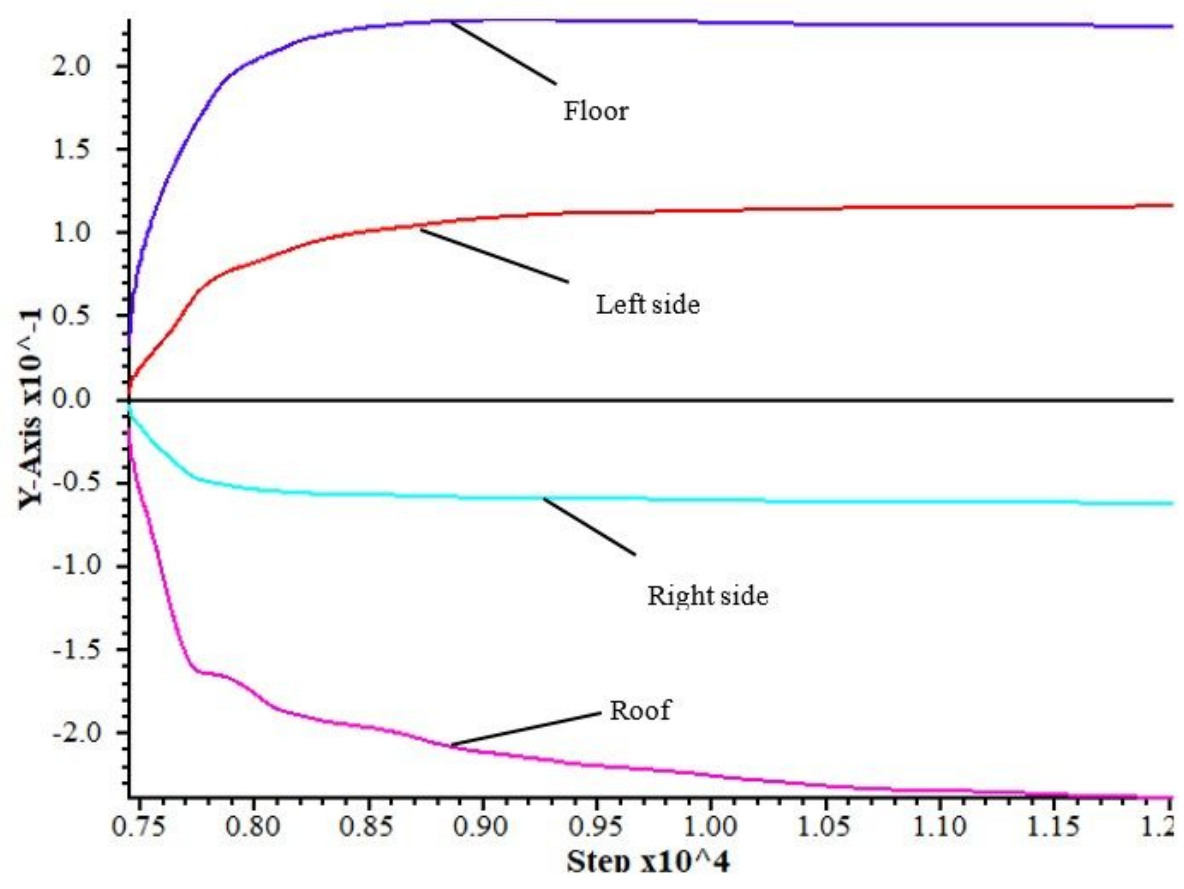

(c)

\section{Figure 9}

numerical calculation results of roadway passing through fault: (a) plastic area after original support (plastic area expands maliciously and support fails); (b) isoline cloud chart of total displacement; (c) convergence curve of monitoring point 


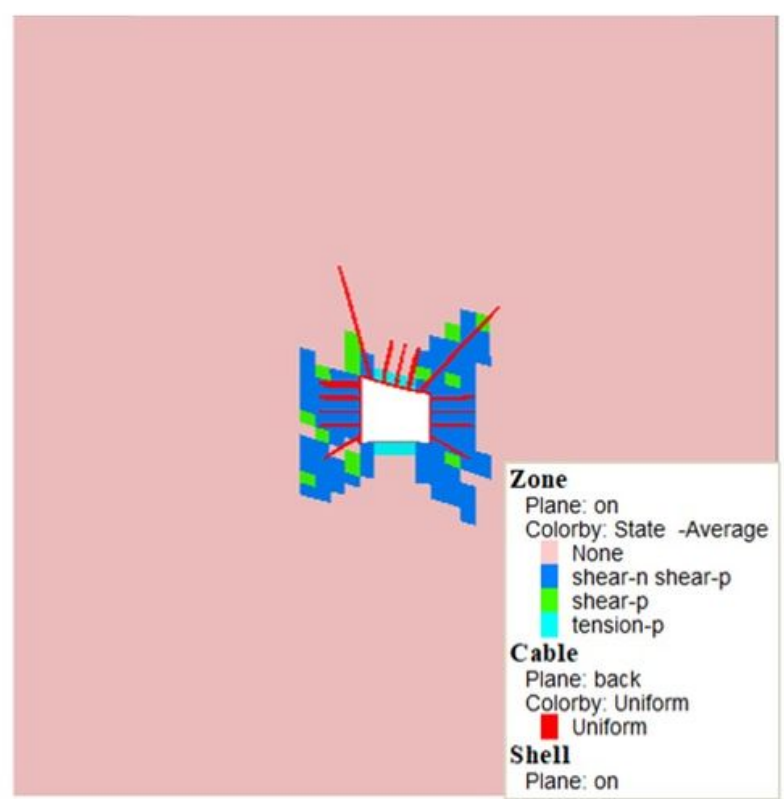

(a)

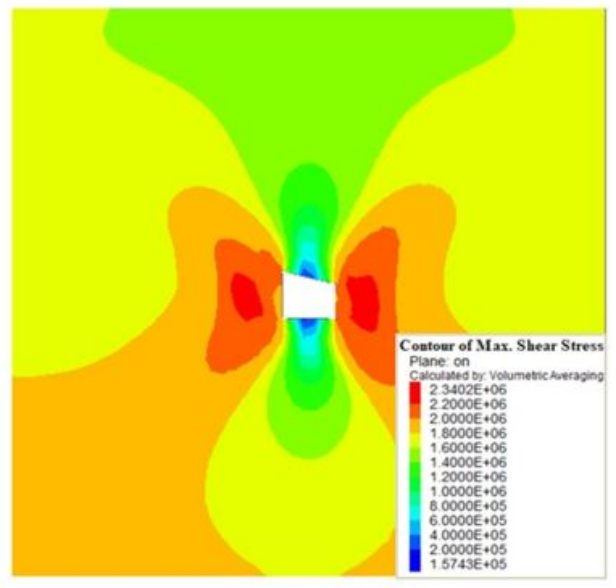

(c)

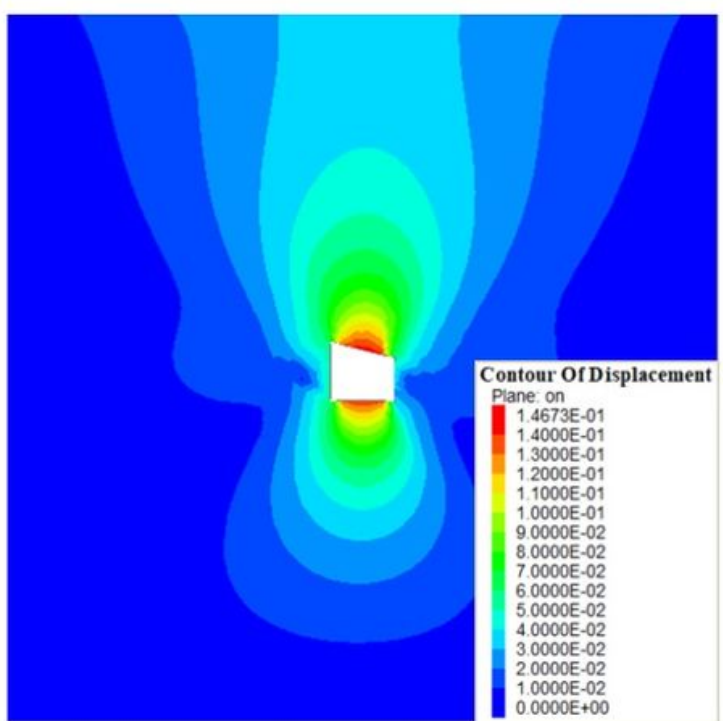

(b)

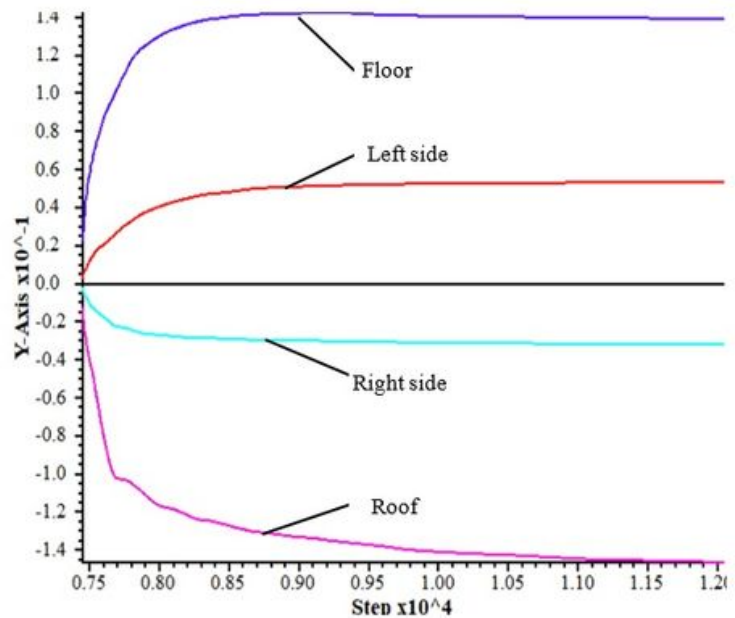

(d)

\section{Figure 10}

Numerical calculation results of the optimal support scheme for roadway passing through faults: (a) plastic zone; (b) contour of total displacement; (c) maximum shear stress; (d) convergence curve of monitoring points 